\title{
Health care barriers for latino children and provision of culturally competent care
}

Jane H. Lassetter

Brigham Young University - Provo, jane_lassetter@byu.edu

Joan H. Baldwin

Brigham Young University - Provo

Follow this and additional works at: https://scholarsarchive.byu.edu/facpub

Part of the Other Nursing Commons, and the Pediatric Nursing Commons

\section{Original Publication Citation}

Lassetter, J. H., \& Baldwin, J. H. (2004). Health care barriers for Latino children and provision of culturally competent care. Journal of Pediatric Nursing, 19(3), 184-192.

\section{BYU ScholarsArchive Citation}

Lassetter, Jane H. and Baldwin, Joan H., "Health care barriers for latino children and provision of culturally competent care" (2004). Faculty Publications. 5177.

https://scholarsarchive.byu.edu/facpub/5177

This Peer-Reviewed Article is brought to you for free and open access by BYU ScholarsArchive. It has been accepted for inclusion in Faculty Publications by an authorized administrator of BYU ScholarsArchive. For more information, please contact ellen_amatangelo@byu.edu. 


\title{
Health Care Barriers for Latino Children and Provision of Culturally Competent Care
}

\author{
Jane H. Lassetter, MSN, RN \\ Joan H. Baldwin, DNSc, RN
}

The demography of the United States is rapidly changing. The impressive growth rate of Latino populations within the United States has great impact on health care. This article includes discussion of a significant increase from 1988 to 2000 in Latino utilization of emergency department and inpatient services at a pediatric medical center in Salt Lake City, Utah, information on health care barriers for Latinos, and suggestions for providing culturally competent care.

(C) 2004 Elsevier Inc. All rights reserved.

$\mathbf{T}$ HE DEMOGRAPHY of the United States is changing rapidly. It has been predicted that Latinos will soon become the largest minority in the nation (Combined News Services, 2001). A Census 2000 brief entitled "Overview of race and Hispanic origin" indicates that this prediction is becoming a reality. Preliminary 2000 census results indicate that the U.S. Latino population totaled 35.3 million, which is approximately $12.5 \%$ of the nation's entire population (U.S. Census Bureau, 2001a). This represents a 58\% growth nationally since the 1990 census (Combined News Services, March 8, 2001). By 2050, it is estimated that Latinos will constitute approximately $25 \%$ of the U.S. population (Flores, Abreu, Olivar, \& Kastner, 1998).

Latino families are often large, with $31 \%$ of Latino households having five or more people, whereas only $12 \%$ of non-Latino white households have five or more members. Additionally, more than $70 \%$ of Latinos are under the age of 40 (Barone, 2001), placing many Latinos in their childbearing years. The birthrate of the Latino population is higher than any other ethnic group and triples that of the overall American population. Children constitute approximately $39 \%$ of the

From the College of Nursing, Brigham Young University, Provo, UT.

Address correspondence and reprint requests to Jane H. Lassetter, MSN, RN, 561 SWKT, College of Nursing, Brigham Young University, Provo, UT 84602. E-mail: jane_lassetter@byu.edu 0882-5963/\$ - see front matter

(C) 2004 Elsevier Inc. All rights reserved.

doi:10.1016/j.pedn.2004.01.007
Latino population in the United States. These numbers indicate that pediatric health care providers are likely to care for increasing numbers of Latino children in their practices (Flores et al., 1998).

In order to provide culturally competent care to this rapidly growing sector of American society, it is necessary to understand factors that influence Latino access to and use of health care. These concepts are multifactorial and are just beginning to be explored in depth. Although there is still much to be learned, a discussion of some of the current thinking and research in this arena is presented in this article. The purposes of this article are (a) to examine emergency department (ED) utilization by Latino children at Primary Children's Medical Center (PCMC) in Salt Lake City, Utah and (b) to suggest methods for ED personnel to assist Latino children and families in overcoming identified barriers and increasing cultural competency of ED personnel with regard to Latino children and families.

Methods used to accomplish these purposes were examining PCMC patient census data and U.S. Census Bureau data, reviewing relevant literature, and interviewing experts. Medline searches were done using the terms Latino, Hispanic, emergency department, and health care barriers. Relevant articles from 1993 to 2002 were retrieved and reviewed. Experts interviewed include S. Fleming, the former Director of Community Outreach at Utah Valley Regional Medical Center in Provo, Utah; L. Cabal, the Interpretation Services Coordinator, PCMC; and Dr. J. Miner, the Medical Director of the Utah County Health Department. 


\section{PCMC EMERGENCY DEPARTMENT UTILIZATION}

\section{Latinos in Utah}

Information from the 2000 Census revealed an amazing growth in the Latino population of Utah. In 1990, there were 84,597 Latinos in Utah, representing $4.9 \%$ of the state's population at that time. Between the 1990 Census and the 2000 Census, the growth rate of the Latino population in Utah was $138.3 \%$, bringing the state's Latino population to 201,559, representing $9.0 \%$ of Utah's total population in 2000 (U.S. Census Bureau, 2001b). In 1999, the U.S. Census Bureau estimated that Latinos represented $7.1 \%$ of Utah's total population (U.S. Census Bureau, 2000). The disparity between the 1999 estimate and the 2000 census data is noteworthy because it demonstrates that the Latino growth rate in Utah surpassed the estimate of experts at the Census Bureau. Additionally, examination of data from the 2000 Census illustrates that Latinos are clearly the largest minority in Utah (U.S. Census Bureau, 2001b).

\section{Latino ED Utilization}

The rapid growth rate in the statewide Latino population is also reflected in PCMC patient census data. However, ethnicity is not asked of patients or parents, but observed and noted by the admitting clerk. Additionally, preadmissions are often completed over the phone. In these cases, ethnicity is not recorded. These omissions result in limitations in analyses of these data.

It is common for Latinos to wait until they are very ill before seeking health care. Often Latinos come to health care providers after home remedies have failed, and illness is interfering with their ability to perform in their social and family roles (de Paula, Laganá, \& Gonzalez-Ramirez, 2001). In addition, Latinos often do not have primary care providers (PCPs). Therefore, when health care is needed, they frequently visit EDs (Adams, 1995; Flores et al., 1998). For these reasons, it was decided to examine PCMC ED utilization by Latino children.

In this hospital, each child is only counted once in the patient census. This means that patients seen in the ED and subsequently admitted as inpatients are only counted as inpatients. Therefore, data on patients seen in the ED and discharged home without inpatient admissions were examined. The number of Latino children using the ED in this manner increased dramatically from 1988 to 2000 (see Figure 1). Calculations were done to determine the Latino percentages of this segment of the ED population (see Figure 2). These percentages also changed substantially between 1988 and 2000. In

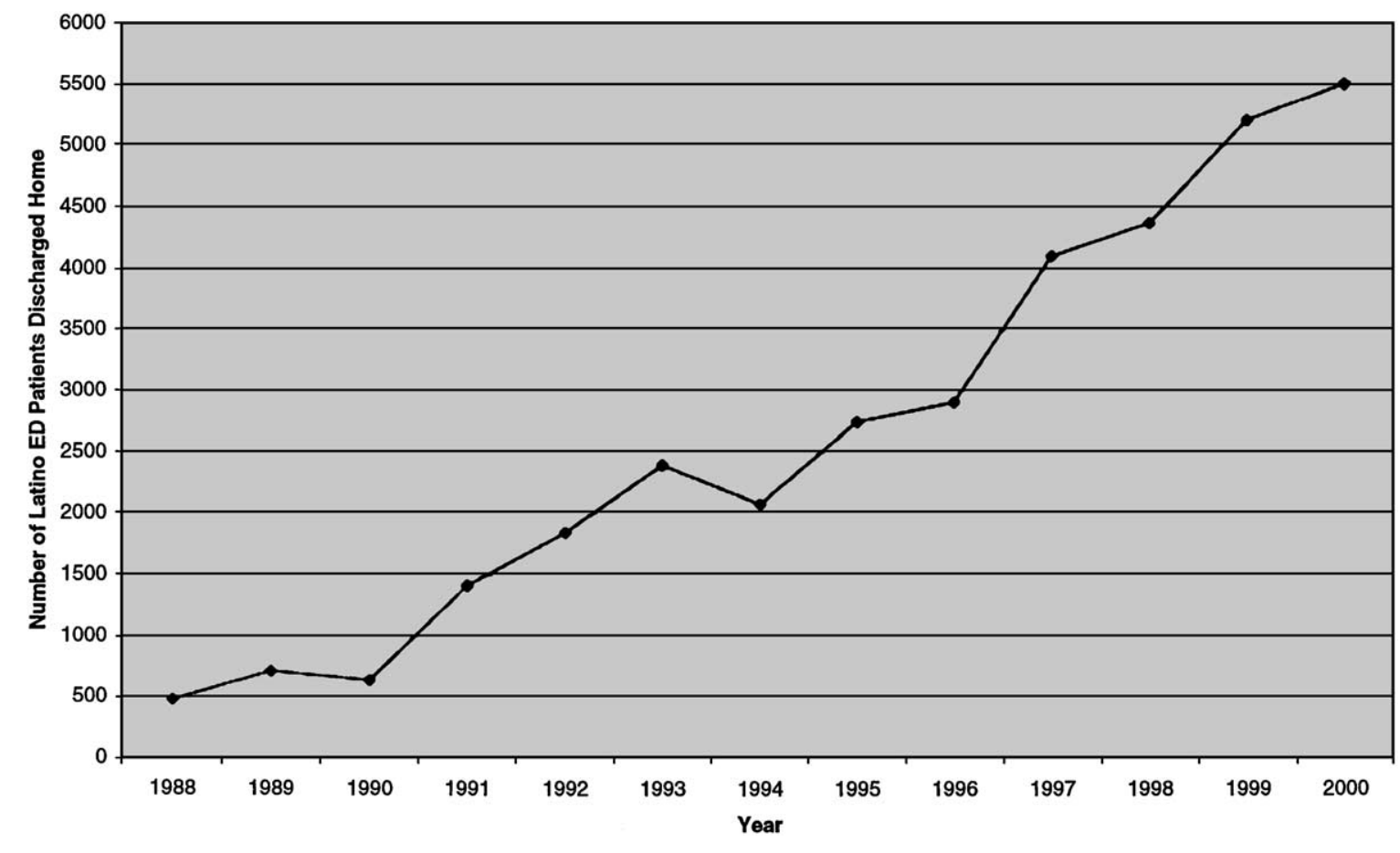

Figure 1. Number of Latino children using PCMC's ED and discharged home without an inpatient admission from 1988 to 2000. 


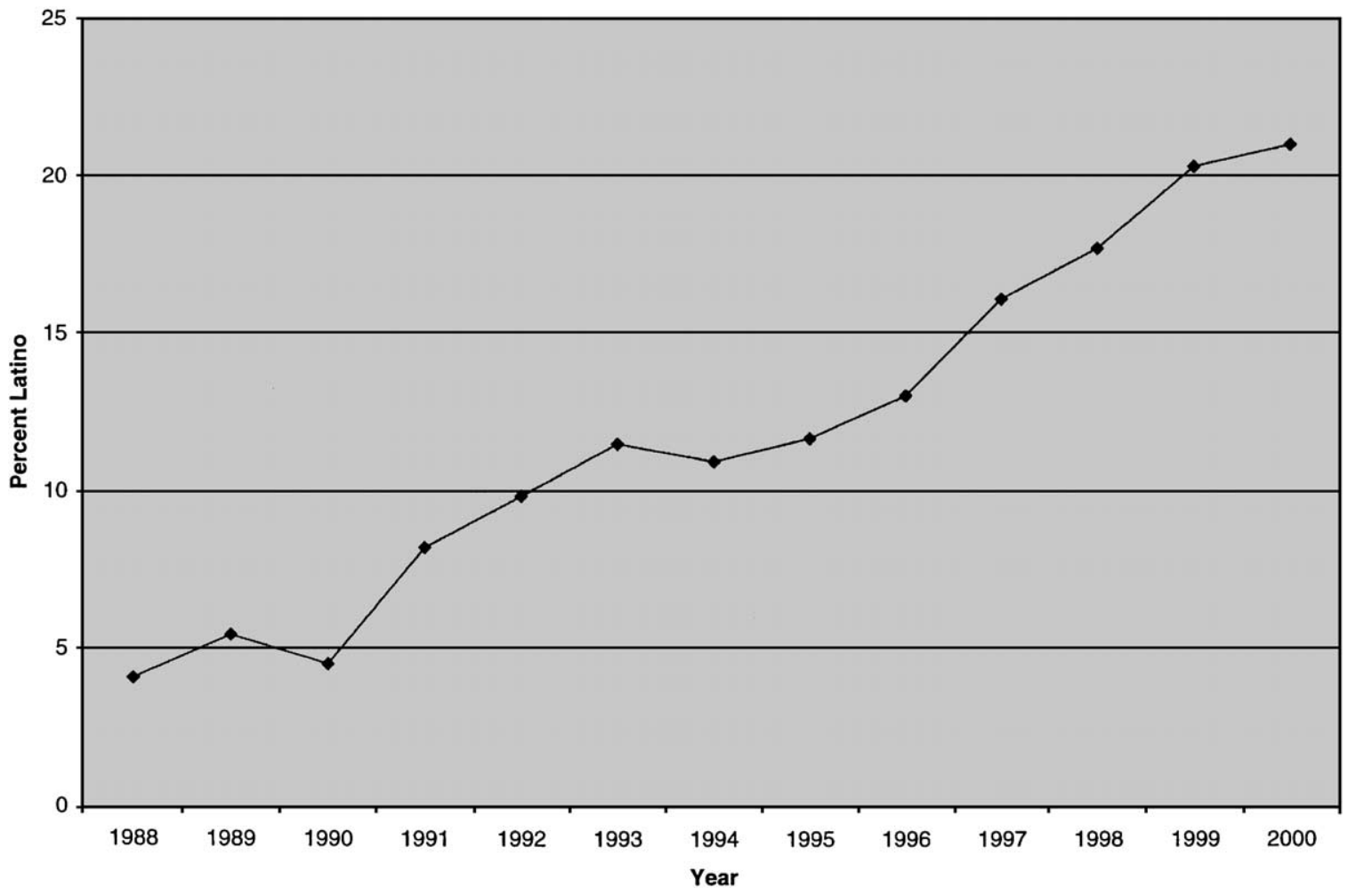

Figure 2. Latino percentages of the portion of PCMC's total ED population discharged home without hospital admission from 1988 to 2000.

1988, 480 Latino children $(4.09 \%$ of the total ED population discharged home) visited the PCMC ED without being admitted as inpatients. Between 1988 and 2000, a greater than tenfold increase in this type of utilization by Latinos occurred (unpublished raw data). In 2000, 5,492 Latino children (20.97\% of the total ED population discharged home) visited the ED without being admitted as inpatients (unpublished raw data).

Comparison of the ED data with data from the 2000 Utah Census Bureau report illustrates that the Latino percentage of the portion of the ED population that was discharged home from PCMC was slightly more than twice the percentage of Latinos found in the community (20.97\% vs. $9.0 \%)$ (U.S. Census Bureau, 2001b; unpublished raw data). This would seem to indicate a need for health education and health promotion among the Latinos in the community to help them maximize their own and their children's wellness and obtain access to other less expensive health care resources.

Flaherty (2000) reported that nationwide $40 \%$ of 1996 hospital admissions of children and youth (excluding infants) were admitted through an ED. Pediatric patients that visit PCMC's ED often re- quire hospital admission. Patient data comparing total Latino inpatient admissions with Latino inpatient admissions in which the ED was the admission source were also studied. These data illustrated that the ED was the source of many Latino hospital admissions from 1988 to 2000 (see Figure 3 ). An upward trend was noted in these data, with 11 Latino children admitted as inpatients from the PCMC ED in 1988. By 2000, this number had increased to 485 children (unpublished raw data). Percentage calculations indicate that $48.26 \%$ of Latino inpatients were admitted from PCMC's ED in 2000.

Data on the number of Latino ED patients discharged home and data on the number of Latino ED patients admitted as inpatients to the hospital were combined to determine a total number of Latino ED patients. Table 1 is a display of the data and calculations on the percentage of Latino ED patients that were admitted as inpatients to the hospital, the average number of Latino ED patients seen per month, and the average number of Latino ED patients seen per day. According to the combined data, approximately 6,000 Latino children visited PCMC ED in 2000, or nearly 500 Latino 


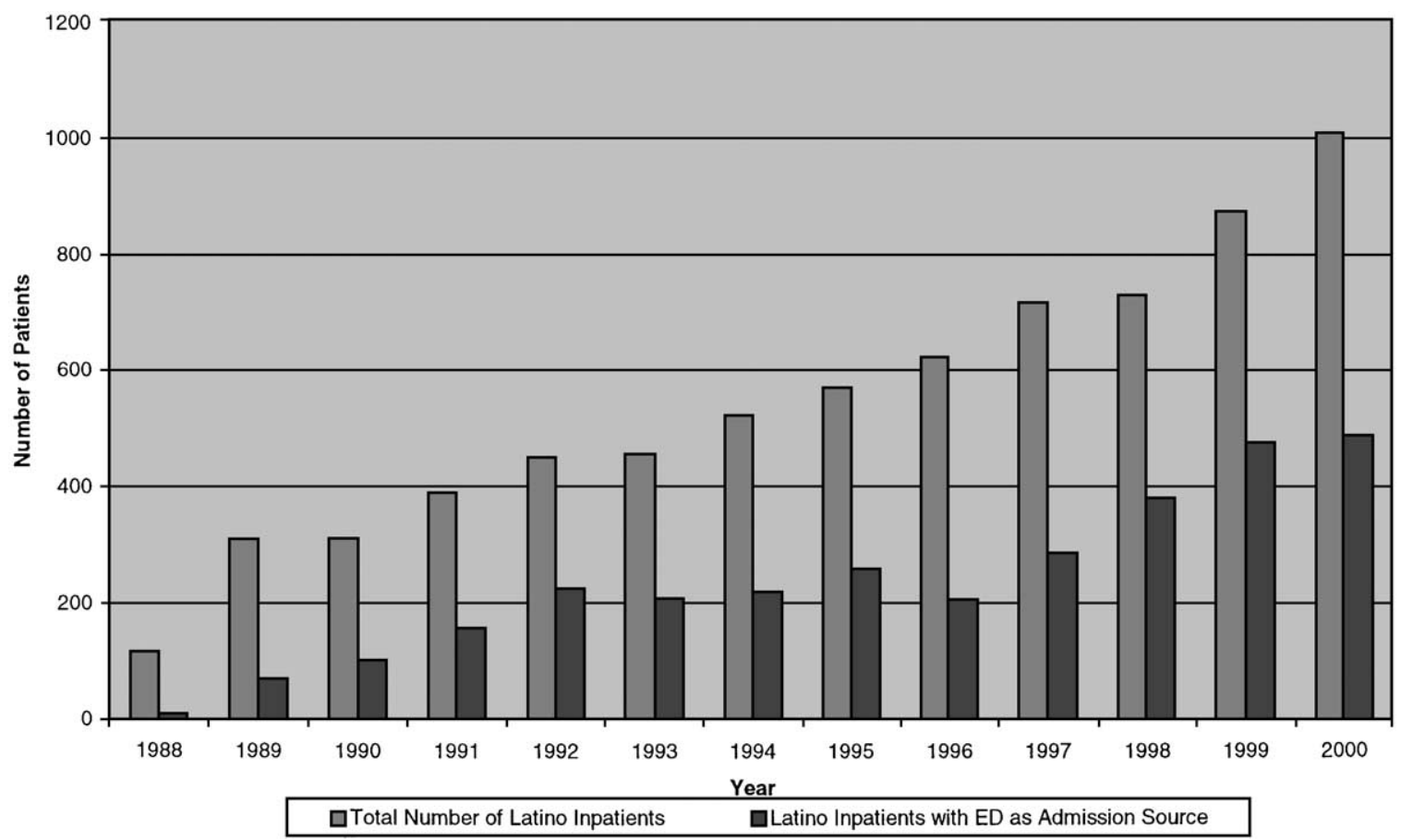

Figure 3. Comparison of Latino inpatient total and number of Latino inpatients with ED as admission source from 1988 to 2000.

children per month. Over the last 3 years, approximately $8 \%$ of the total number of Latino children who visited the ED required an inpatient admission. The other $92 \%$ were discharged home (unpublished raw data). These data suggest that many Latino children are visiting the ED in place of a PCP in the community and further verify the need for health promotion efforts among them. Latino utilization of the ED instead of visiting a PCP is also noted in the literature (Adams, 1995; Flores et al., 1998; Zambrana, Ell, Dorrington, Wachsman, \& Hodge, 1994). For instance, Flores et al. (1998) found that $21 \%$ of Latino children in their study visited an ED for routine sick visits.

\section{OVERCOMING IDENTIFIED BARRIERS AND INCREASING CULTURAL COMPETENCY}

These data all point to a need for education on health promotion among Latinos in the community. Such efforts, especially if combined with provision of more PCPs near Latino population centers, may help Latino children and parents maximize their wellness and obtain access to more appropriate and cost-effective care when needed.

Table 1. Number of Latino ED patients 1988-2000

\begin{tabular}{ccccccc}
\hline Year & $\begin{array}{c}\text { \# of Latino ED patients } \\
\text { discharged home }\end{array}$ & $\begin{array}{c}\text { \# of Latino ED patients } \\
\text { admitted to hospital }\end{array}$ & $\begin{array}{c}\text { Total Latino } \\
\text { ED patients }\end{array}$ & $\begin{array}{c}\text { Percentage of total } \\
\text { Latino ED patients } \\
\text { admitted to hosp }\end{array}$ & $\begin{array}{c}\text { Patients/month } \\
\text { (total/12) }\end{array}$ & $\begin{array}{c}\text { Patients/day } \\
\text { (total/365) }\end{array}$ \\
\hline 1988 & 480 & 11 & 491 & 2.24 & 40.92 & 1.35 \\
1989 & 712 & 71 & 783 & 9.06 & 65.25 & 2.15 \\
1990 & 641 & 103 & 744 & 13.84 & 62.00 & 2.04 \\
1991 & 1416 & 159 & 1575 & 10.10 & 131.25 & 4.32 \\
1992 & 1846 & 227 & 2073 & 10.95 & 172.75 & 5.68 \\
1993 & 2397 & 210 & 2607 & 8.06 & 217.25 & 7.14 \\
1994 & 2078 & 221 & 2299 & 9.61 & 191.58 & 6.30 \\
1995 & 2749 & 261 & 3010 & 8.67 & 250.83 & 8.25 \\
1996 & 2908 & 207 & 3115 & 6.65 & 259.58 & 8.53 \\
1997 & 4100 & 286 & 4386 & 6.52 & 365.50 & 12.02 \\
1998 & 4367 & 381 & 4748 & 8.02 & 395.67 & 13.01 \\
1999 & 5197 & 476 & 5673 & 8.39 & 472.75 & 15.54 \\
2000 & 5492 & 485 & 5977 & 8.11 & 498.08 & 16.38 \\
\hline
\end{tabular}


Additionally, increasing numbers of Latino patients affirm that it is essential and timely for health care providers to become more culturally competent in caring for Latino pediatric patients (Adams, 1995; S. Fleming, personal communication, March 16, 2001).

One of the major strengths of Latinos is their strong family support systems. They are very helpful to one another. Children are highly valued, and the entire family often becomes involved in raising them. This may be especially evident when a child becomes ill. It is not unusual for many family members to accompany a child to the hospital or to an appointment with a health care provider. Decision making often requires consultation among the entire family (de Paula et al., 2001; L. Cabal, personal communication, March 13, 2001).

\section{Language Barriers}

When a child and/or parents are unable to speak English, a health care practitioner often has to diagnose and treat without an accurate or complete history. A prospective cohort study in Chicago found that the presence of a language barrier was correlated with a $\$ 38$ increase in diagnostic testing and a 20-minute longer stay in the ED. Language barriers were most often identified among Latinos in this study (Hampers, Cha, Gutglass, Binns, \& Krug, 1999).

Language barriers clearly have significant impact on health care. Despite this, only two states (Minnesota and Washington) provide Medicaid reimbursement for interpretation services. However, pursuant to Title VI of the Civil Rights Act of 1964, the Office of Civil Rights stipulates that recipients of federal financial assistance, which includes most health care institutions, must provide people with limited English proficiency with meaningful opportunities to participate. They further state that interpretation services be readily available during all hours of operation (Flores, 2000). This certainly would apply to the need for interpreters in pediatric EDs.

One ideal solution for the language barrier problem would be for medical and nursing schools to require applicants and/or graduates to be fluent in a language, other than English, that would be helpful in their practice (Flores \& Mendoza, 2002). Until such a goal becomes reality, classes in Spanish emphasizing medical terminology can be offered to employees in an effort minimize the language barrier that is so often a part of caring for Latino children (Flores et al, 1998). In addition, interpre- tation service requests should be tracked, and new interpreters should be hired as needed.

Lack of medical interpreters can be conquered through increased training and partnering with the Latino community (Flores et al., 1998). There are several volunteer interpreters at PCMC, who complete a short course to become familiar with the expectations of the role. Likely there will be a need to increase the number of volunteer interpreters as the Latino population continues to multiply.

Health promotion education among Latinos could be offered in Spanish or in a bilingual combination of Spanish and English. For example, patient-teaching aids, such as pamphlets, could be available in both English and Spanish. It would be helpful for these materials to be located for easy patient access in hospital lobbies, in the ED as well as other units, and perhaps in chapels, cafeterias, and other places patients and families might frequent. PCMC has an educational series of health care information titled, "Let's Talk About," that is accessible on PCMC's intranet in both English and Spanish. Education on how to locate and print bilingual information for patients could be provided for ED staff and families.

\section{Understanding Latino Culture}

Lack of understanding of the Latino culture by health care providers has frequently been a deterrent for parents in seeking health care for their children and has been noted as a dissatisfier among Latino patients (Flores et al., 1998). One report stated that Latinos who believed they were poorly treated by health care providers were 1.9 times more likely to have used EDs (Wagner \& Guendelman, 2000).

Normative cultural values, including the concepts of simpatía and respeto, have been identified among Latinos and very frequently affect clinical care, especially in EDs. Within the concept of simpatía, politeness, pleasantness in stressful situations, and avoiding hostile confrontations are highly valued. Based on this concept, Latinos expect the health care provider to have a positive attitude. When the provider displays a relatively neutral attitude, it can be interpreted negatively by Latinos (Flores et al., 1998). This may cause the parents to withhold information, not adhere to recommended treatments, miss follow-up appointments, and be dissatisfied with care (Flores, 2000).

Emphasizing courtesy and politeness can help assure simpatía. Latinos appreciate having a warm, personal relationship with health care providers. This would include shaking hands, having interac- 
tions that occur at close distance, and beginning conversations with a brief discussion of the patient's family or other interests (Flores, 2000).

Within the concept of respeto, Latinos see physicians as authority figures to be given respect. Sometimes Latino respect for medical professionals precludes them from informing health care providers about home remedies because they fear offending the health care provider (de Paula et al., 2001). Latinos may also demonstrate respeto by hesitancy in asking questions. Questioning an authority figure, such as a health care provider, may be viewed as disrespectful by Latinos. Therefore, silence may indicate a lack of understanding or agreement with plan of care (de Paula et al., 2001). In addition, Latinos may sometimes nod their heads, indicating to the health care provider that they either agree with or understand what the health care provider is saying. However, in reality, the Latinos may not understand or agree with what is being said. Nodding the head is often a sign of respect or an indication the person has heard the health care provider (Flores, 2000).

In return for their respect, reciprocal respect is expected, especially if the parent is older than the health care provider. When a physician or other care provider fails to use respectful terms and/or does not elicit parental concerns, negative perceptions may develop leading to dissatisfaction with care (Flores et al., 1998). In addition, parents and patients who do not feel that they have been given the proper respect are more prone to nonadherence with treatment plan and inadequate follow-up (Flores, 2000). To show respect, health care providers should use appropriate titles, such as Senor and Senora, when addressing parents and use formal greetings, such as buenos dias (good morning) and buenos tardes (good afternoon). Involving the parents in medical decisions and carefully eliciting their concerns are very important in showing proper respect. Also, health care providers need to remember the importance of extended family in decision making and, whenever possible, provide sufficient time for family members to convene and discuss medical decisions (Flores, 2000).

Fatalismo, another Latino cultural value, is the belief that there is little an individual can do to alter fate. This may be seen through decreased utilization of preventative screening among Latinos and evasion of effective therapies, including those offered in the ED. Health care providers can help avoid these adverse consequences by stressing the rationale and importance of screening and the efficacy of therapies. A health care provider might use the patient's cultural beliefs in achieving these goals by suggesting that God may not want the patient to be sick or die at this particular time (Flores, 2000). It may be helpful to engage the family's priest or minister in counseling about this issue as well.

\section{Latino Folk Illnesses}

Folk illnesses are often seen in EDs and may be similar to or conflict with biomedical illness and can have clinical ramifications. Latino childhood folk illnesses are commonly encountered by health care providers, including in the ED setting (Flores, 2000). Having a clear understanding of beliefs, customs, and traditions that mold Latino views of health and illness is indispensable when diagnosing and planning treatments and interventions. In fact, failure to understand health beliefs and practices can be considered a breach of professional standards of practice. In some states, when a patient does not follow prescribed treatment plans because they are in conflict with patient's values and beliefs, a presumption of negligence on the part of the provider is raised (Ahmann, 2002).

Vomiting, diarrhea, bloating, fever, and chills are the symptoms (Flores \& Vega, 1998) of empacho, a Latino folk illness that affects the gastrointestinal tract. It is believed that something gets trapped inside the stomach as the result of a dietary indiscretion like overeating or eating the wrong food or eating at a bad time. Folk remedies may include dietary modifications, administration of herbal tea, massaging the abdomen with warm oil, and popping the skin on the lower back. Most folk remedies for empacho are clinically harmless. However, there are some powdered remedies that contain high concentrations of lead oxide; and one type of tea that is made from wormwood leaves and is a cerebral stimulant that can cause psychosis and premature death. It is also important to note that symptoms of empacho could be the same as symptoms of biomedical conditions such as gastroenteritis, intussuseption, pyloric stenosis, and appendicitis (Flores, 2000). Awareness by ED staff of the potential use of these harmful remedies can be very helpful when assessing Latino children.

While interacting with a Latino child, ED care providers need to be certain to touch the child and, at the same time, be aware of mal ojo, or evil eye. Mal ojo is believed to occur when someone with "strong eyes" looks at a child and places a spell on him/her. The spell causes the child's blood to heat resulting in crying, fever, diarrhea, and vomiting (Flores, 2000; Flores \& Vega, 1998). People with 
green eyes are thought to be especially capable of inflicting mal ojo. In addition, admiring a child without touching him/her is believed to put the child at greater risk for mal ojo (de Paula et al., 2001).

In one study among Mexican-American parents, the researcher reported mal ojo as the most common folk illness experienced, with $70 \%$ of participants stating that they had encountered mal ojo. Treatment included visiting a folk healer for rituals and herbal remedies or lightly brushing the body with a lemon, egg, or chili pepper. Symptoms of mal ojo (crying, fever, diarrhea, and vomiting) are also common to several biomedical conditions, such as gastroenteritis, bacteremia, sepsis, and dehydration seen so often in pediatric patients in EDs (Flores, 2000).

Some parents protect against mal ojo by placing an amulet on a necklace or bracelet placed on infant. This practice can put the infant at risk for strangulation and can present problems for surgery and other medical procedures. A safe and culturally sensitive suggestion would be to pin the amulet to the inside of a child's garment during certain procedures (Flores, 2000). Certainly, concerns regarding the risks must be discussed with the family members before removing the amulet in any way. These suggestions may seem difficult in most hectic, ED situations; however, the cultural sensitivity demonstrated will lessen much of the parents' and other family members' fears.

Mollera caida, or fallen fontanels, common in dehydration and thus often seen in the ED, is thought to take place when the breast or bottle is removed from an infant's mouth too quickly (Flores \& Vega, 1998). As a result, the infant experiences difficulty swallowing, fever, diarrhea, and fussiness. Folk treatments, aimed at "realigning" the fontanels, include pushing up the soft palate with the thumb, pulling the hair, sucking on the fontanels, and tapping the feet while hanging the infant over a basin of water. The last two treatments can be fatal, with death resulting from subdural hemorrhage (Flores, 2000).

The ED health care providers' approach to the issue of folk illness and remedies has a great impact on patient satisfaction, adherence to the treatment plan, and continuity of care. An important step toward cultural competency is generating awareness among ED staff of the existence of various folk illnesses within a cultural group. This is crucial because the symptoms of folk illnesses and biomedical conditions are often similar. Acknowledging the parents' concerns regarding folk illnesses may pave the way to explore possible additional biomedical conditions. Increasing cultural sensitivity can be achieved by asking patients and parents about folk illness beliefs, discussing cultural issues with colleagues belonging to the ethnic group, studying published studies regarding cultural beliefs, and discussing culture with interpreters and community members from specific ethnic groups (Flores, 2000).

Flores (2000) recommends the following 4-step approach for nonjudgmental discussion of folk illness beliefs with patients and families: (a) recognizing that there is a folk illness or illness common to the Latino culture of which the health care providers may not be aware, (b) asking whether the parents are familiar with illnesses common to their culture, (c) asking whether it is believed that the child has this illness currently, and if so, (d) asking what home remedies or other treatment the child is receiving. It is important to remember that many folk remedies are not dangerous. Instead of attempting to have all of the harmless folk remedies terminated, health care providers should emphasize using the biomedical treatments in addition. When potentially harmful folk remedies are being used, health care providers can carefully describe the concerns and potential harm and, whenever possible, suggest substituting a harmless folk remedy that fits with the family's belief system. Medical treatment plans and etiology of the disease need to be thoughtfully explained with particular emphasis on the rationale for suggested interventions (Flores, 2000).

\section{Increasing Cultural Competency}

Developing a climate of cultural competency within health care organizations can be very challenging. Nationally, health care organizations are struggling to meet these challenges and are at various levels of awareness along the cultural competence continuum. Very few systematically incorporate cultural competency into policy making, administration, service delivery, and consumer levels (Ahmann, 2002). Cultural awareness and cultural competency need to become a more integral part of caring for patients. It is crucial that awareness of folk illnesses and remedies, previously discussed (Ahmann, 2002), be generated among the ED staff. This is especially important because the ED is the initial point of contact between the traditional health care arena and many Latinos.

An important step in establishing a climate of cultural competency would be to hold focus groups with representatives from the Latino community to 
discuss their health care needs and what improvements could be made in care to provide more culturally sensitive care (Ahmann, 2002). In addition, focus groups to conduct a needs assessment with Latino families could be done. They should be asked what things they would change and what could be done to improve their experience. Questions could also be asked about how their cultural and spiritual needs might best be met (S. Fleming, personal communication, March 16, 2001). Often there are Latinos who were health care professionals in their own countries who may or may not be continuing to practice in the United States; these professionals can be of great value in teaching about the health care and cultural beliefs to those health care professionals who are not of that particular culture.

To keep research expense at a minimum, agencies, such as Americorp, which, in the state of Utah, is affiliated with the Association of Utah Community Health, and other community health groups nationally, could assist with such a study for a small stipend. Individuals join Americorp, a federal program, out of a desire to help people. Americorp is largely funded through grants from the Robert Wood Johnson Foundation. The individuals could be trained as research assistants and perform the interviews. Obviously, Americorp workers who are able to speak Spanish and English would be most helpful, especially if they are from a Latino culture. Although a focus group completed in this manner may seem difficult to achieve, local experts feel that Americorp workers would be able to help in this reachable and worthwhile goal (S. Fleming, personal communication, March 16, 2001, J. Miner, November, 2002). This study suggestion is consistent with Ahmann's (2002) recommendation that the racially, ethnically, culturally, and linguistically diverse groups be identified and their satisfaction with care and the degree to which they access care be determined.

Perhaps cultural competency measures could be developed and built into job evaluations. In addition, providing Grand Rounds or brown bag lunches on different cultures and associated health beliefs and health practices would help disseminate much needed information. Similarly, employee orientation and workshops should include information about the Latino culture (Ahmann, 2002). Again, collaboration with the Health Department as well as university language departments would help minimize the expense of offering such classes (S. Fleming, personal communication, March 16, 2001).

A multidisciplinary task force could be helpful in improving cultural competency. Among other things, such a task force could develop protocols of care for various cultural groups.

Expenditure requirements for resource and professional development need to be identified and included in the budget each fiscal year (Ahmann, 2002). Utilization of the ED for routine care and underutilization of appropriate and needed health care services are extremely costly. Therefore, health promotion efforts among the Latino population have the potential to save the health care system thousands of dollars.

\section{SUMMARY}

The demography of the nation and state of Utah are rapidly changing. Demographic changes in the nation and the state have direct impact on the demography of the patient population of PCMC. The data plainly illustrate that an ever-increasing portion of the patient base of this hospital is Latino by ethnicity. To best care for this rapidly growing section of the community, health care providers need to grasp opportunities to learn more about Latino culture and find or create appropriate methods of promoting health among Latinos.

PCMC has an environment of caring for children best described by the philosophy of the medical center, "The child first and always." It is important to acknowledge the changing population in the community and prepare to meet the needs of all children by respecting their families' cultural beliefs regarding disease and health care and integrating these beliefs with the best culturally competent care.

\section{REFERENCES}

Adams, L. (1995). Hispanics are the fastest-growing population- and patient-segment. Emergency Medical Services, 10, 57-59.

Ahmann, E. (2002). Developing cultural competence in health care settings. Pediatric Nursing, 28, 133-137.

Barone, M. (2000, March 19). The many faces of America: The surge of Hispanics is changing the way we think of ourselves as a nation. U.S. News \& World Report, 130, 118-20.
Combined News Services (2001, March 8). Latinos may be No. 1 minority. The Salt Lake Tribune. Retrieved March 14, 2001, from http://www.sltrib.com/2001/mar/03082001/nation_ w/77663.htm.

de Paula, T., Laganá, K., \& Gonzalez-Ramirez, L. (2001). Mexican Americans. In J.G. Lipson, S.L. Dibble \& P.A. Minarik (Eds.), Culture \& Nursing Care: A Pocket Guide. San Francisco: University of California San Francisco Press. 
Flaherty, L. (2000). Report issued on health care of America's children [from the Feds]. Journal of Emergency Nursing, 26, 356-357.

Flores, G. (2000). Culture and the patient-physician relationship: Achieving cultural competency in health care. The Journal of Pediatrics, 136, 14-23.

Flores, G., \& Mendoza, F.S. (2002). ¿Dolor aqui? ¿Fiebre?: A little knowledge requires caution. Archives of Pediatrics \& Adolescent Medicine, 156, 638-640.

Flores, G., \& Vega, L.R. (1998). Barriers to health care access for Latino children: A review. Family Medicine, 30, 196-205.

Flores, G., Abreu, M., Olivar, M.A., \& Kastner, B. (1998). Access barriers to health care for Latino children. Archives of Pediatric and Adolescent Medicine, 152, 1119-1125.

Hampers, L.C., Cha, S., Gutglass, D.J., Binns, H.J., \& Krug, S.E. (1999). Language barriers and resource utilization in a pediatric emergency department. Pediatrics, 103, 1253-1256.
U.S. Census Bureau (2000). State and county quickfacts. Retrieved March 20, 2001, from http://quickfacts.census.gov/ qfd/states/49000.html.

U.S. Census Bureau (2001a). Overview of race and Hispanic origin. Retrieved March 20, 2001, from http://www.census.gov/ population.

U.S. Census Bureau (2001b). Census 2000, Redistricting data (P.L. 94-171) summary file. Retrieved March 22, 2001, from http://www.census.gov/ clo/www/redistricting.html.

Wagner, T.H., \& Guendelman, S. (2000). Healthcare utilization among Hispanics: Findings from the 1994 Minority Health Survey. The American Journal of Managed Care, 6, 355-364.

Zambrana, R.E., Ell, E., Dorrington, C., Wachsman, L., \& Hodge, D. (1994). The relationship between psychosocial status of immigrant Latino mothers and emergency pediatric services. Health Social Work, 19(2), 93-102. 